\title{
Bibliometric analysis of medicine-related publications on poverty (2005-2015)
}

\author{
Waleed M. Sweileh ${ }^{*}$, Samah W. Al-Jabi ${ }^{2}$, Ansam F. Sawalha' ${ }^{1}$, Adham S. AbuTaha ${ }^{1}$ and Sa'ed H. Zyoud ${ }^{2}$
}

\begin{abstract}
Background: Poverty is a global problem. The war against poverty requires not only financial support, but also poverty-related research to pinpoint areas of high need of intervention. In line with international efforts to fight poverty and negative consequences, we carried out this study to give a bibliometric overview of medicine-related literature on poverty. Such a s study is an indicator of the extent of interaction of various international key players on the war against poverty-related health problems.

Methods: Scopus was used to achieve the objective of this study. The time span set for this study was 2005-2015. Poverty-related articles under the subject area "Medicine" were used to give bibliometric indicators such as annual growth of publications, international collaboration, highly cited articles, active countries, institutions, journals, and authors.

Results: The total number of retrieved articles was 1583. The Hirsh-index of retrieved articles was 56. A modest and fluctuating increase was seen over the study period. Visualization map of retrieved articles showed that "HIV", infectious diseases, mental health, India, and Africa were most commonly encountered terms. No significant dominance of any particular author or journal was observed in retrieved articles. The United States of America had the largest share in the number of published articles. The World Health Organization and Centers for Disease Prevention and Contro/ were among top active institutions/organizations. International collaboration was observed in less than one third of publications. Top cited articles focused on three poverty-related health issues, mainly, infectious diseases, malnutrition, and child development/psychology. Most of top articles were published in high impact journals.
\end{abstract}

Conclusions: Data indicated that articles on poverty were published in high influential medical journals indicative of the importance of poverty as a global health problem. However, the number publications and the extent of international collaborations was lower than expected given the huge burden of poverty-related health problems.

Keywords: Poverty, Bibliometric analysis, Health journals

\section{Background}

Poverty is a global problem and the fight against poverty is a worldwide responsibility (Ferreira and Ravallion 2008; Kim and Chan 2013). Poverty is present everywhere, even in developed countries (Pritchett 2014). According to World Health Organization (WHO), more than one billion people in the word have an income of less than one dollar a day. The WHO is working with

\footnotetext{
*Correspondence: waleedsweileh@yahoo.com

${ }^{1}$ Department of Physiology, Pharmacology, and Toxicology, College of Medicine and Health Sciences, An-Najah National University, Nablus, Palestine

Full list of author information is available at the end of the article
}

poor countries to implement health policies that prioritize health needs of poor people (World Health Organization 2016). A wide range of communicable and non-communicable diseases such as parasitic, nutritional, neurodevelopmental and cardiovascular diseases have been linked to poverty (Kalichman et al. 2014; Marmot 2016). At the global level, acquired immune deficiency syndrome (AIDS), malaria, and tuberculosis are major poverty-related diseases. These diseases are found mainly in poor developing countries such as sub-Saharan Africa (Buve et al. 2002; MacDonald 2005; Whiteside 2010; von Philipsborn et al. 2015). Many of neglected tropical diseases such as leprosy, lymphatic filariasis, 
chagas disease, trypanosomiasis, onchocerciasis, schistosomiasis, helminthiasis, leishmaniasis, and trachoma are mainly present in poor communities (Hotez et al. 2006, 2008; Feasey et al. 2010; Hotez et al. 2012). Centers for Disease Control and Prevention (CDC) have identified these diseases as public health priority given the large number of people infected with these diseases (Centers for Disease Prevention and Control 2016). Poor nutrition, respiratory diseases, and cardiovascular diseases are major non-communicable diseases associated with poverty. It is estimated that one third of children in subSaharan Africa showed physical signs of malnutrition (Piwoz and Preble 2000). Malnutrition can negatively affect the immune system and thus increase the risk of human immunodeficiency virus infection and its transmission from mothers to newborn (Friis and Michaelsen 1998). Poverty itself can be considered as major risk factor for many diseases and as a barrier for economic development (de la Barra 1998; Piazza 2006; Hilson 2009).

An important aspect in the war against poverty is research that sheds light on poverty and its association with physical and mental health especially in children and pregnant women. In fact, at least four peer reviewed journals are specialized in publishing research related poverty. Such journals include, Infectious Diseases of Poverty, Journal of Poverty, The Journal of Poverty and Social Justice, and Journal of Children and Poverty. Publications on health-related aspects of poverty constitute a database for each country in order to formulate its strategic health plans and to prioritize its agenda accordingly. Poverty is considered a top agenda for many international health agencies. Actually, the Millennium Development Goals (MDG) launched in year 2000 by the United Nations had eight goals to be accomplished in year 20015. One of these goals, the first goal, was to eradicate extreme poverty and hunger. The MDG is now over and it is time to assess how countries, institutions, and international agencies reacted to this goal in the past years from a research and publication point of view. The volume of literature produced on poverty-related health issues is considered an indicator of international responsibility toward poor countries and an indicator of the amount of efforts implemented to fight poverty-related diseases. In line with international efforts to eliminate poverty and its related medical and health consequences, we participated in this study to assess research growth and highlight most important topics on poverty-related health issues. Furthermore, this study is part of global efforts needed to shed light on poverty as a public health issue.

Bibliometric analysis is a tool used to assess the quantity and quality of research output on a certain topic (Thompson and Walker 2015). Bibliometric analysis on medicine-related poverty literature will give an idea on the volume of literature on this topic and content of articles that are being mostly cited in this field. Furthermore, bibliometric analysis will shed light on network of authors and co-authorship that will help finding research partners across the globe for potential collaboration and joint grant seeking. Bibliometric analysis is also an important indicator of the impact of governmental and non-governmental initiatives on war against poverty and its consequences (Thompson and Walker 2015; Thompson and Clark 2015). Therefore, the objective of this study was to give a bibliometic overview on medicinerelated literature on poverty using Scopus search engine. Specifically, the number of publications, top active countries and institutions, highly cited articles, citation analysis, international collaboration, top active authors, and journals involved in publishing articles on poverty will be presented.

\section{Methods}

This study was carried out using one of the largest and up-to-date electronic databases, Scopus. In bibliometric studies, researchers can use any of the existing databases such as PubMed or Web of Science (WoS) or Pubmed to retrieve required data. It is the authors understanding that Scopus offers advantages over other databases. For example, the volume of literature available through Scopus is higher than that available through PubMed or WoS. Furthermore, Scopus provides citation analysis and a friendly search engine. Scopus is produced by Elsevier and covers more than 20,000 journals and has $100 \%$ Medline coverage. Scopus offers about 20\% more coverage than WoS, whereas Google Scholar offers results of inconsistent accuracy (Falagas et al. 2008). Discussion regarding these databases is beyond the scope of this manuscript. Further details and comparison of advantages and disadvantages of each database have been published (Falagas et al. 2008).

In this study, poverty was the only concept in this study. However, we did not search for all publications on poverty. Rather, search was limited to medicine-related publications on poverty. To achieve this, search strategy was based on poverty concept followed by limiting the findings to publications in journals categorized in Scopus as "Medicine". In this search strategy, we do not need to do intersection between results obtained from different concepts. The approach was made easy and reproducible using Scopus functions which can help in limiting and refining results to achieve the required goal. For example, Scopus has a function called "Subject" which includes "medicine" as well as other subjects that the researcher can limit the findings to. Furthermore, Scopus has 
functions like time span, source type, and type of documents. In each function, Scopus allows the researcher to limit and refine data in a reproducible way. For the current study, the reproducibility of data can be achieved by inserting the chosen keywords in advanced search in Scopus followed by refining results using the functions explained in details in subsequent paragraphs. At any time, the number of publications retrieved by any other researchers will be almost the same as presented in result section with very slight change that might be due to continuous updating of Scopus system. Regarding the total number of citations for retrieved articles, it is changeable with time because citation is a dynamic process. For this reason, all information pertaining to total number of citations and $h$-index are valid at the time specified in the study.

The first step and the most crucial one in any bibliometric analysis is the identification of keywords that will yield the highest number of retrieved articles with minimum false negative or false positive results. The selected keywords to be used in this study were those related to poverty which include: poverty or "out-of-pocket payments" or "catastrophic payments". These selected keywords were entered in Scopus search engine in title search. The use of these keywords in title search aimed at increasing accuracy. However, these keywords are not considered enough to filter false negative results. Therefore, we added another condition to the search query. The keyword poverty was used again as a conditional term for the title search mentioned above. Therefore, Scopus will search for keywords like poverty or "out-of-pocket payments" or "catastrophic payments" in article title and will retrieve only articles in which the word "poverty" was also mentioned in abstract or keyword list. The ultimate search query looked like this: TITLE (poverty OR "outof-pocket payments" OR "catastrophic payments") AND TITLE-ABS-KEY (poverty). The keyword "food insecurity" could fit within the search query for this study. However, when "food insecurity" keyword was used, an extra 200 articles were retrieved. However, many of these articles were not poverty related and those that were poverty related were already retrieved. Therefore, the highest accuracy scenario was the one presented above that would achieve minimum acceptable error. Furthermore, poverty and food insecurity are not the same (Wight et al. 2014).

The second step in bibliometric analysis is to limit the time span of the study and to refine retrieved data. The time span for this study was set from year 2005 to year 2015. Research on poverty has been carried out for decades and we expect that the volume of literature on poverty will be huge. Therefore, specifying the time period from 2005 to 2015 will make the amount of data retrieved reasonable to handle. Furthermore, in the past decade or so, many wars, political unrest, internal conflicts were witnessed in most parts of the world especially Middle East and Africa and these wars created massive numbers of refugees and internally displaced people living in camps under poor conditions that can lead to various types of diseases. Therefore, we consider the specified period for the study to be justifiable and relevant.

The third step was to refine data by excluding books, book chapters and errata (correction) documents which can be accomplished easily using the refine and limit functionalities in Scopus. The purpose of this step was to restrict the analysis to literature in peer reviewed journals. Journal articles are considered original and novel work and that is why we focused on journal articles rather than books or book chapters. Furthermore, in any topic, the percentage of documents published as chapters or books is very small compared to journal articles. The validity of the search strategy was confirmed by manual review of a sample of 300 retrieved articles selected across the time span of the study.

The fourth step in the methodology of this study was to limit retrieved data to articles under subject area "Medicine". Scopus classifies retrieved articles into different subject areas, one of which is "Medicine". For the purpose of this study, only articles categorized under subject area 'Medicine" were analyzed. Therefore, articles under "Medicine" subject area in which poverty was the main theme were retrieved and analyzed.

The fifth step in bibliometric analysis was to carry out analysis to present the required bibliometric indicators which include the followings: (1) types of published documents, (2) languages, (3) annual growth of publications, (4) citation analysis, (5) active countries, institutions, journals and authors, (6) International collaboration, (7) most frequent terms, and (8) highly cited articles. Some of these parameters were presented as tables, and some were presented as figures while others were presented as visualization map using VOSviewer technique (van Eck and Waltman 2010). For each of these parameters, further explanation will be presented in result section.

In this study, international collaboration was defined as an article being published by at least two authors with two different country affiliation. Of course, Scopus database has the country affiliation for each author in every published article and allows country analysis through tables or maps easily once that data are exported to Microsoft Excel software. In this regard, Scopus allows us to identify publications with multiple country affiliations 
and publications with single country affiliation. Single country publications (SCP) are articles in which all authors have the same country affiliation and such publications represent intra-country collaboration. Multiple country publications (MCP) are articles in which authors have different country affiliation and such publications represent inter-country collaboration.

For citation analysis, total citations for retrieved articles, average number of citations per article, percentage of highly cited articles, and Hirsch $(h)$ index were presented (Hirsch 2005). These indicators are considered an indirect assessment of quality where high $h$-index and number of citations might be considered as an indicator of high quality. For assessing impact of publications in different journals, the impact journal (IF) of the publishing journal was used. The IF was retrieved from the latest Journal Citation Report published by Thompson Reuters. Highly cited articles were obtained from Scopus by sorting retrieved data based on number of citations then exporting whatever number of articles to Microsoft Excel for tabulation and then to Endnote for appropriate referencing. The standard competition ranking (SCR) was used to rank top ten active countries, institutions, and authors. Whenever necessary, data pertaining to $\mathrm{SCP}$ and $\mathrm{MCP}$ were also presented.

The sixth and last step in bibliometric analysis is seeking ethical approval to carry out the study. In the case of bibliometrics, where no human subjects or data were involved, the institutional ethical committee asked for no ethical approval for such a study. Figure 1 shows a scheme for data retrieval for this study with numbers showing how many documents were retrieved in each step.

\section{Results}

\section{General data}

A total of 1583 journal articles were retrieved (Fig. 1). Two thirds ( $\mathrm{n}=1075 ; 67.91 \%)$ were research articles while the remaining were review articles, letters, notes, editorials, short surveys and articles in press. Table 1 shows the various types of retrieved documents. The total number of different languages used in publishing retrieved articles was 15. The primary language was English (1426; 90.08\%). Other languages like French, Italian, German, Spanish, Portuguese, Polish, Japanese, Chinese and Turkish were also encountered. Table 2 shows the list of encountered languages in retrieved articles. Retrieved articles received a total of 17,131 citations, an average number of 10.82 citations per article. The $h$-index of retrieved articles was 56. A total of 1114 (70.37\%) articles were cited at least once while the remaining 469 (29.63\%) were not cited at all.
Search query: TITLE (poverty OR "out-ofpocket payments" OR "catastrophic payments") AND TITLE-ABS-KEY (poverty)

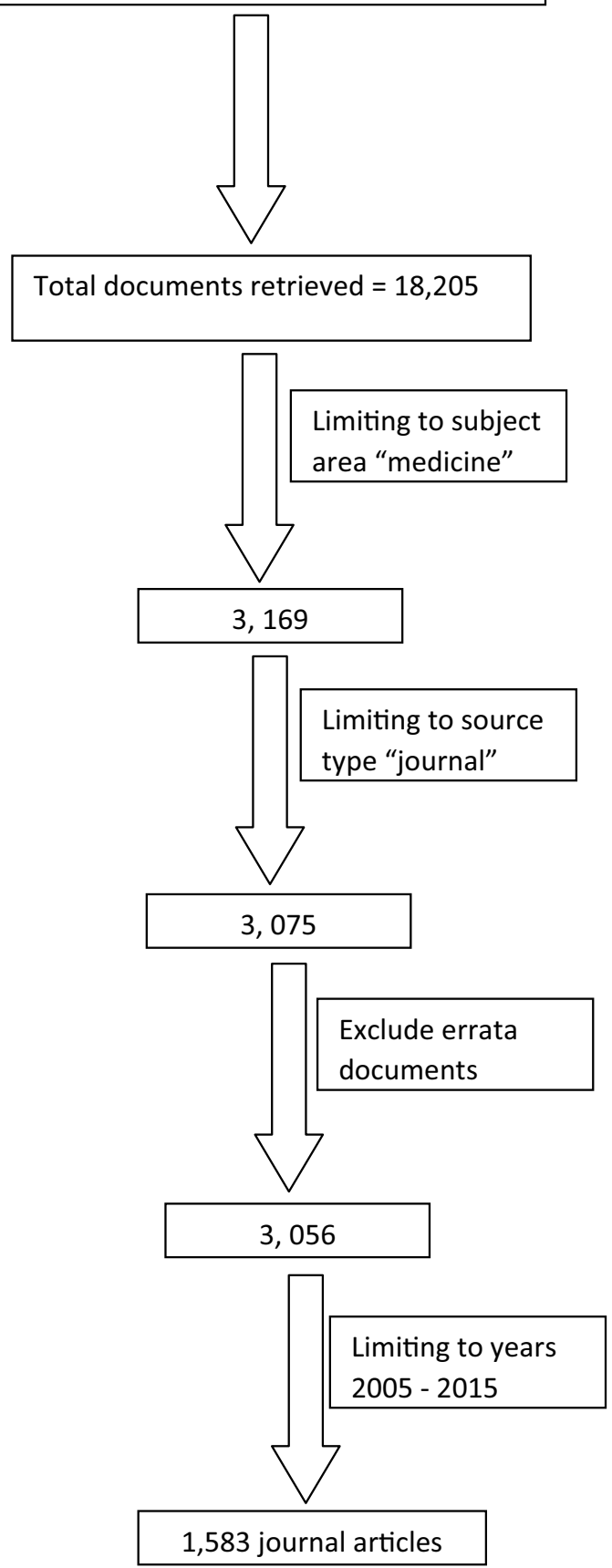

Fig. 1 Scheme showing search strategy to obtain publications on medicine-related publications (2005-2015). Search strategy was based on keywords related to poverty and the results were refined based on subject "medicine", source type "journal articles, time span "2005-2015" and excluding errata documents 
Table 1 Types of retrieved documents on poverty (20052015)

\begin{tabular}{lcc}
\hline Type of document & Frequency & $\%$ \\
\hline Article & 1075 & 67.91 \\
Review & 154 & 9.73 \\
Editorial & 147 & 9.29 \\
Note & 87 & 5.50 \\
Letter & 49 & 3.10 \\
Short survey & 25 & 1.58 \\
Conference paper & 24 & 1.52 \\
Article in press & 22 & 1.39 \\
\hline
\end{tabular}

Table 2 languages of retrieved articles on poverty (20052015)

\begin{tabular}{lcc}
\hline Language & $\begin{array}{l}\text { Total number of } \\
\text { documents }\end{array}$ & $\mathbf{( \% )}^{\mathbf{a}}$ \\
\hline English & 1426 & 90.08 \\
Spanish & 51 & 3.22 \\
Portuguese & 32 & 2.02 \\
German & 30 & 2.0 \\
Chinese & 27 & 1.70 \\
French & 23 & 1.45 \\
Italian & 9 & 0.57 \\
(Norwegian, Czech, Danish, Swedish, & 16 & 1.07 \\
$\quad$ Turkish, Croatian, Japanese, Korean, & & \\
$\quad$ Slovenian) & & \\
\hline
\end{tabular}

a Total percentages might exceed $100 \%$ because some articles are written in 2 languages in the abstract and title and therefore some overlap might exist

\section{Publications with time}

During the study period, the annual number of published articles on poverty increased slightly and in a fluctuating manner. The highest number of published articles was in
2007 with a total of 237 articles. Table 3 shows the number of retrieved articles per year along with their citation analysis. Table 3 shows that articles published in 2005 had the highest average number of citations per article while those published in 2015 had the least number of citations per article.

\section{Most frequently encountered terms}

Retrieved articles were analyzed for most commonly encountered terms in title and abstract of retrieved articles. The frequent terms were visualized using VOSviewer. Figure 2 shows a visualization map of most frequently related terms. The map consists of three clusters of terms presented in different colors. The green cluster included terms such as ethnicity, socioeconomic status, neighborhood poverty, rural area and infection. The red cluster included terms such as Africa, India, HIV, cost, policy and infection. The blue cluster included terms such as childhood poverty and mental health.

\section{Countries}

A total of 94 countries participated in publishing retrieved articles. Table 4 shows top 10 active countries in publishing medicine-related poverty documents. The top 10 active countries participated in publishing a total of 1187 (74.98\%). The United States of America (USA) $(589 ; 37.21 \%)$ had the greatest share of publications followed by the United Kingdom (UK) (174; 10.99\%), and Canada $(103 ; 6.51 \%)$. The USA was also the leading country in the annual number of publications from 2005 to 2015. More than half $(54.5 \%)$ of worldwide articles on medicine-related poverty publications were produced by the USA, the UK and Canada. Countries like South Africa, Australia, Brazil, India, and China were also listed within the top 10 active countries.

Table 3 Annual number of published articles and citations analysis (2005-2015)

\begin{tabular}{|c|c|c|c|c|c|c|c|c|}
\hline Year & $\begin{array}{l}\text { Total number } \\
\text { of articles }\end{array}$ & $\%$ & TC & C/A & $\begin{array}{l}\text { Number of articles } \\
\text { with citations }\end{array}$ & $\%$ & $\begin{array}{l}\text { Number of articles } \\
\text { with no citations }\end{array}$ & $\%$ \\
\hline 2015 & 205 & 12.95 & 347 & 1.69 & 96 & 46.83 & 109 & 53.17 \\
\hline 2014 & 179 & 11.31 & 565 & 3.16 & 109 & 60.89 & 70 & 39.11 \\
\hline 2013 & 145 & 9.16 & 860 & 5.93 & 105 & 72.41 & 40 & 27.59 \\
\hline 2012 & 124 & 7.83 & 890 & 7.18 & 93 & 75.00 & 31 & 25.00 \\
\hline 2011 & 116 & 7.33 & 1478 & 12.74 & 89 & 76.72 & 27 & 23.28 \\
\hline 2010 & 144 & 9.10 & 1999 & 13.88 & 113 & 78.47 & 31 & 21.53 \\
\hline 2009 & 127 & 8.02 & 1936 & 15.24 & 97 & 76.38 & 30 & 23.62 \\
\hline 2008 & 131 & 8.28 & 1956 & 14.93 & 110 & 83.97 & 21 & 16.03 \\
\hline 2007 & 238 & 15.03 & 2791 & 11.73 & 161 & 67.65 & 77 & 32.35 \\
\hline 2006 & 105 & 6.63 & 2467 & 23.50 & 81 & 77.14 & 24 & 22.86 \\
\hline 2005 & 69 & 4.36 & 1822 & 26.41 & 58 & 84.06 & 11 & 15.94 \\
\hline
\end{tabular}

$T C$ total citations, $C / A$ number of citations per article calculated by dividing the total number of citations retrieved for each year by the total number of publications in that year 


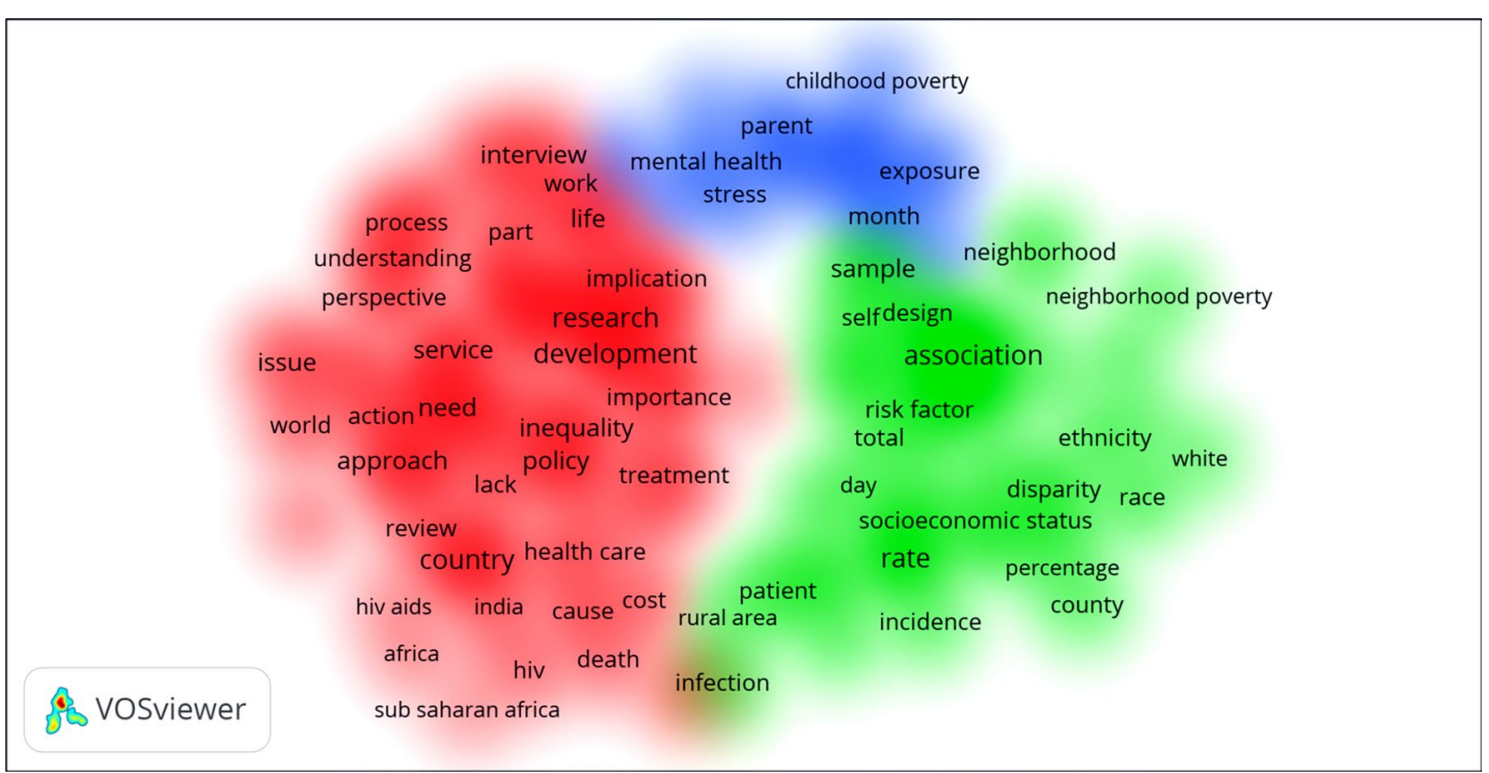

Fig. 2 Density visualization map of most frequently related terms in retrieved articles

Table 4 Top 10 active countries in number of publications (2005-2015)

\begin{tabular}{|c|c|c|c|c|c|c|c|c|}
\hline $\mathrm{SCR}^{\mathrm{a}}$ & Country & Number of articles & $\%$ & NCC & MCP & $\%$ & SCP & $\%$ \\
\hline $1 s t$ & United States & 589 & 37.21 & 62 & 127 & 21.56 & 462 & 78.44 \\
\hline 2nd & United Kingdom & 174 & 10.99 & 50 & 94 & 54.02 & 80 & 45.98 \\
\hline $3 r d$ & Canada & 103 & 6.51 & 32 & 39 & 37.86 & 64 & 62.14 \\
\hline 4th & South Africa & 76 & 4.80 & 27 & 37 & 48.68 & 39 & 51.32 \\
\hline 5 th & Australia & 59 & 3.73 & 31 & 28 & 47.46 & 31 & 52.54 \\
\hline 6th & India & 44 & 2.78 & 36 & 22 & 50.00 & 22 & 50.00 \\
\hline 7th & Brazil & 43 & 2.72 & 9 & 15 & 34.88 & 28 & 65.12 \\
\hline 8th & China & 39 & 2.46 & 19 & 18 & 46.15 & 21 & 53.85 \\
\hline 9th & Germany & 31 & 1.96 & 16 & 15 & 48.39 & 16 & 51.61 \\
\hline 10th & Switzerland & 29 & 1.83 & 33 & 26 & 89.66 & 3 & 10.34 \\
\hline
\end{tabular}

NCC number of collaborating countries, SCP single country publication (intra-country collaboration), MCP multiple country publications (inter-country publications)

a $S C R$ Standard competition ranking. Equal countries were given the same ranking number, and then a gap is left in the ranking numbers

International (inter-country) collaboration was also shown in Table 4. Although the USA had the highest number of collaborating countries $(n=62)$, articles from USA had the least percentage of inter-country collaboration calculated as percentage of multiple country publication (MCP). For the USA, approximately $79 \%$ of articles were published by domestic authors presented as percentage of single country publication (SCP). On the other hand, approximately $90 \%$ of articles produced by researchers from Switzerland, for example, had coauthors from different countries. For the top 10 active countries a total of $421(35.47 \%)$ articles were MCP suggestive of international collaboration while $64.53 \%$ of published articles by top 10 active countries were SCP.

\section{Authors and institutions}

Top active authors who published most were from different countries (Table 5). No major dominance of any particular author was seen in this field and no single author had major contribution over other researchers. Analysis of top 10 active authors also showed that three authors were from the USA, three from Australia, two from Canada, one from South Africa and one from the UK. Similarly, there were no major dominance of any particular institution for research in poverty over other institutions, although London School of Hygiene $\mathcal{E}$ Tropical Medicine in the UK ranked first in number of publications, number of citations and $h$-index (Table 6). The difference between the top 10 active intuitions in the number of publications was not large. 
Table 5 Top 10 prolific authors publishing on povertyrelated health issues (2005-2015)

\begin{tabular}{lllll}
\hline SCR $^{\mathbf{a}}$ & Author & Frequency & $\%$ & Country \\
\hline 1st & Hotez, P.J. & 16 & 1.01 & USA \\
2nd & Callander, E.J. & 11 & 0.69 & Australia \\
2nd & Schofield, D.J. & 11 & 0.69 & Australia \\
4th & Séguin, L. & 10 & 0.63 & Canada \\
5th & Lund, C. & 9 & 0.57 & South Africa \\
5th & Schootman, M. & 9 & 0.57 & USA \\
5th & McClellan, W.M. & 9 & 0.57 & USA \\
8th & Shrestha, R.N. & 8 & 0.51 & Australia \\
9th & Emerson, E. & 7 & 0.44 & UK \\
9th & Gauvin, L. & 7 & 0.44 & Canada \\
\hline
\end{tabular}

USA United States of America, UK United Kingdom

a SCR Standard competition ranking. Equal countries were given the same ranking number, and then a gap is left in the ranking numbers

\section{Highly cited articles}

The top 20 highly cited articles on medicine-related poverty publications were presented in Table 7 . Of the top 20 list, 14 were research articles and four were review articles, one was editorial and one was a conference paper. The article which received the highest number of citations was "Neighborhood racial composition, neighborhood poverty, and the spatial accessibility of supermarkets in metropolitan Detroit" (Zenk et al. 2005) published in American Journal of Public Health. The article received a total of 439 citations up to the time of data analysis (September 15, 2016). The topics covered in top
20 cited articles were infectious diseases, mental health, nutrition, and development as related to poverty.

\section{Journals}

The total number of different journal names which published a minimum of three articles on poverty was 117 . A total of 316 (19.96\%) articles were published in the top 20 active journals (Table 8 ) which suggests that there was no major dominance of any particular journal over others in publishing articles on poverty-related health issues. In fact, most of the journals in the top 20 list were either in general medicine or in public health field. The journal that has the largest share of publications was Lancet $(\mathrm{n}=32)$ while the American Journal of Public Health received the greatest number of citations and Tropical Medicine and International Health journal had the highest average number of citations per article. Table 8 also shows the IF for the top 20 active journals. The highest IF value in 2015 was that of Lancet which had an IF value of 44. All journals in the top 20 list are indexed in ISI Thompson Reuters and some of them had high IF suggestive of the great medical importance of poverty on individual and population health.

\section{Discussion}

In this study, a bibliometric overview of medicinerelated poverty publications was presented. The use of Scopus search engine in this study was justifiable given the advantages it has over other databases (Falagas et al. 2008). Literature search identified two studies on bibliometrics as related to poverty. However, these two

Table 6 Top 10 productive institutions on poverty in health-related journals (2005-2015)

\begin{tabular}{|c|c|c|c|c|c|c|}
\hline $\mathrm{SCR}^{\mathrm{a}}$ & Institution & Frequency & $\%$ & Country affiliation & TC & $h$ index \\
\hline 1st & London School of Hygiene \& Tropical Medicine & 34 & 2.15 & UK & 848 & 18 \\
\hline 2nd & The University of North Carolina at Chapel Hill & 31 & 1.96 & USA & 577 & 12 \\
\hline $3 r d$ & Universite de Montreal & 24 & 1.52 & Canada & 149 & 7 \\
\hline $3 r d$ & Harvard School of Public Health & 24 & 1.52 & USA & 701 & 13 \\
\hline 5 th & University of Cape Town & 23 & 1.45 & South Africa & 327 & 8 \\
\hline 6th & University of California, San Francisco & 22 & 1.39 & USA & 299 & 10 \\
\hline 6th & Organisation Mondiale de la Sante & 22 & 1.39 & $\mathrm{WHO}$ & 929 & 11 \\
\hline 8th & University of Toronto & 21 & 1.33 & Canada & 235 & 8 \\
\hline 9th & University of Illinois at Chicago & 19 & 1.20 & USA & 774 & 11 \\
\hline 10th & Johns Hopkins Bloomberg School of Public Health & 18 & 1.14 & USA & 485 & 11 \\
\hline 10th & University of KwaZulu-Natal & 18 & 1.14 & South Africa & 217 & 8 \\
\hline 10th & Centers for Disease Control and Prevention & 18 & 1.14 & CDC/USA & 597 & 9 \\
\hline 10th & The University of Sydney & 18 & 1.14 & Australia & 55 & 4 \\
\hline
\end{tabular}

TC total citations, $h$-index Hirsch index, USA United States of America, UK United Kingdom, WHO World Health Organization, CDC Centers for Disease Control and Prevention

a $S C R$ standard competition ranking. Equal countries were given the same ranking number, and then a gap is left in the ranking numbers 


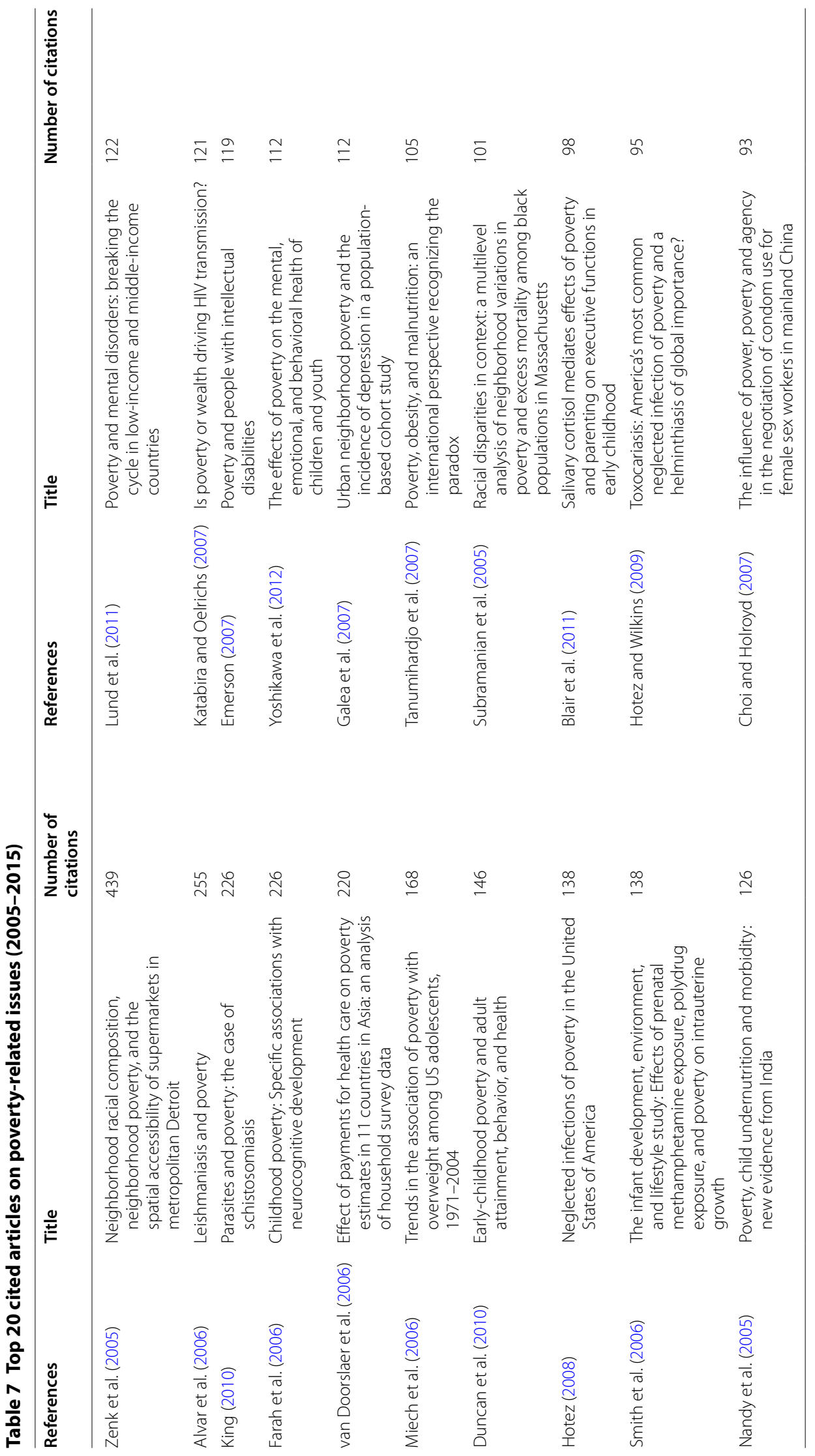


Table 8 Top 20 health-related journals publishing on poverty-related health issues (2005-2015)

\begin{tabular}{|c|c|c|c|c|c|c|}
\hline $\mathrm{SCR}^{\mathrm{a}}$ & Journal & Frequency & $\%$ & $\mathrm{TC}$ & C/A & IF \\
\hline $1 \mathrm{st}$ & Lancet & 32 & 2.02 & 620 & 19.38 & 44.002 \\
\hline 2nd & American Journal of Public Health & 26 & 1.64 & 864 & 33.23 & 2.24 \\
\hline $3 r d$ & Plos One & 25 & 1.58 & 207 & 8.28 & 3.54 \\
\hline 4th & Health and Place & 20 & 1.26 & 254 & 12.70 & 1.74 \\
\hline 5 th & Social Science and Medicine & 19 & 1.20 & 530 & 27.89 & 2.814 \\
\hline 6 th & BMC Public Health & 18 & 1.14 & 216 & 12.00 & 2.209 \\
\hline 7th & Plos Neglected Tropical Diseases & 18 & 1.14 & 564 & 31.33 & 4.446 \\
\hline 7th & Journal of Epidemiology and Community Health & 16 & 1.01 & 220 & 13.75 & 3.31 \\
\hline 9th & BMJ Clinical Research $E d^{b}$ & 15 & 0.95 & 17 & 1.13 & 17.4 \\
\hline 10th & Ciencia E Saude Coletiva & 14 & 0.88 & 71 & 5.07 & 0.50 \\
\hline 11 th & Bulletin of The World Health Organization & 13 & 0.821 & 435 & 33.46 & 5.089 \\
\hline 12th & International Journal for Equity in Health & 12 & 0.758 & 70 & 5.83 & 2.378 \\
\hline 13th & Tropical Medicine and International Health & 11 & 0.695 & 386 & 35.09 & 2.519 \\
\hline 14th & Journal of Urban Health & 10 & 0.632 & 154 & 15.40 & 2.046 \\
\hline 14th & Paediatrics and Child Health & 10 & 0.632 & 46 & 4.60 & 1.477 \\
\hline 14 th & Pediatrics & 10 & 0.632 & 320 & 32.00 & 5.473 \\
\hline 14th & Preventing Chronic Disease & 10 & 0.632 & 51 & 5.10 & 2.170 \\
\hline 14 th & Salud Publica De Mexico & 10 & 0.632 & 35 & 3.50 & 1.107 \\
\hline 19th & International Journal of Health Services & 9 & 0.569 & 42 & 4.67 & 0.782 \\
\hline 19th & Journal of Health Care for The Poor and Underserved & 9 & 0.569 & 52 & 5.78 & 0.924 \\
\hline 19th & Plos Medicine & 9 & 0.569 & 225 & 25.00 & 14.429 \\
\hline
\end{tabular}

TC total citations, C/A average number of citations per article calculated by dividing the total citation by number of articles for each journal, IF impact factor

a $S C R$ standard competition ranking. Equal countries were given the same ranking number, and then a gap is left in the ranking numbers

b Discontinued in 1988. Currently it is known as BMJ (British Medical Journal)

studies were directed to either assessment of collaboration between European countries and African countries on research pertaining to neglected tropical and infectious diseases or toward implementation of research on diseases of poverty (Gonzalez-Block et al. 2011; Breugelmans et al. 2015). Neither of these studies assessed the worldwide publications on poverty and its relation to health. It should be emphasized that there are thousands of publications on poverty in non-medical subject area such as politics, economy, social studies and religion that were not considered in this study. In our study, we focused on poverty literature within the subject "Medicine".

The number of publications slightly increased over the study period. It is evident that most governmental and non-governmental funding goes to research domains in infectious diseases, nutritional disorders and neurodevelopmental growth but not to poverty per se. The peak of research productivity seen in 2007 is difficult to explain and we are unable to determine whether this peak is due to a surge in domestic violence and wars with the spread of thousands of refugees and poverty or it is just an unexplained coincidence. Despite all this, most publications about poverty were published in highly prestigious and influential journals such as Lancet. Furthermore, the importance of "poverty" as a research topic in social sciences, psychology and community health was emphasized by the introduction of specialized journals such as Journal of Poverty, Journal of Poverty and Social Justice, and Journal of Children and Poverty. In this study, no major dominance of any particular journal regarding number of publications was seen suggesting that poverty is a wide concept affecting various health issues. For example, many journals in the field of parasitology and infectious diseases published articles on poverty (Alvarado-Esquivel et al. 2013). Similarly, many journals in the field of nutrition, psychology and public health published similar articles on poverty and its relation to health (Bhattacharya et al. 2004). Finally, the presence of nonEnglish articles is another indicator of worldwide growing interest in the medical and social aspects of poverty.

Analysis of publications showed that countries in Latin America, Africa, and Asia had contributed to this field (Szwarcwald et al. 2002; Das et al. 2007). This is not surprising given that poverty is common in countries like India, Brazil, and Africa in general. International collaboration among the top 10 active countries was modest with approximately approximately one 
third of articles had multiple country affiliation. International collaboration in research is highly needed and should be encouraged since most low and middle income countries cannot fund such research and might not have the advanced technical and medical tools used to investigate poverty-related diseases or health issues. Furthermore, international collaboration increases the quality of publications and chances of articles to be cited and published in high impact journals (Huamani et al. 2015).

Analysis of top cited articles revealed that most retrieved articles addressed issues of neglected diseases, particularly parasitic diseases. Other topics found in top cited articles were those pertaining to nutrition, child psychology and mental development. The number of people being affected with infectious diseases in low and middle income countries is high and many countries have implemented health policies to control such common diseases by reducing poverty rates (Calisher 2007; Huntington 2012). It was not surprising that such articles were published in highly prestigious general journals simply because it is estimated that one billion people worldwide are living below the poverty line. As expected, the World Health Organization and its affiliated Journal (Bulletin of the World Health Organization) had a good share of publications in this field.

Density visualization map showed that a group of articles had linked poverty with development, neurocognitive, intelligence, behavioral, and mental health. A study had shown that higher socioeconomic status was associated with better performance on neurocognitive tests (Farah et al. 2006). Another study had linked poverty with childhood brain development and academic achievement. The authors of that study argued that families with low income should be targeted to avoid heavy cost of poor academic achievement (Hair et al. 2015). The association between family poverty and mental health and behavior of children have been investigated and authors argued that mental health programs need to be scaled up (Lund et al. 2011). Poverty have been associated with drinking alcohol, violence, smoking, stress and depression (Grant et al. 2005; Lovisi et al. 2005; Haustein 2006; Wheeler et al. 2006; Perese 2007; Mossakowski 2008; Mulia et al. 2008; Tracy et al. 2008; Kinyanda et al. 2011; Nikulina et al. 2011).

Another group of articles on poverty have linked poverty with infectious diseases, particularly HIV and parasitic diseases. Of these particular infectious diseases, leishmaniasis, schistosomiasis, malari, toxocariasis and tuberculosis were strongly linked to poverty (Grant et al. 2005; Lovisi et al. 2005; Haustein 2006; Wheeler et al. 2006; Perese 2007; Mossakowski 2008; Mulia et al. 2008; Tracy et al. 2008; Kinyanda et al. 2011; Nikulina et al. 2011). The association between poverty in one hand and drug abuse and HIV on the other hand have been extensively investigated. A study claimed that chances of poor people being exposed to HIV are not necessarily greater than wealthier individuals or households and that HIV hit across all socioeconomic strata (Katabira and Oelrichs 2007). The association between poverty and HIV/AIDS is best exemplified by the situation in Africa (Kalichman et al. 2005; Tladi 2006; Mbirimtengerenji 2007; Nattrass 2009; Thurlow et al. 2009; Fox 2010; Shisana et al. 2010; Tsai et al. 2013). Even some of the serious global viral diseases like Ebola and Dengue have been linked to poverty (Khun and Manderson 2008; Fallah et al. 2015). Association between poverty and infectious diseases is not present only in Africa but even in Europe, India, China, Latin America and the USA (Jackson et al. 2006; Riley et al. 2007; Silveira et al. 2008; Gryseels et al. 2009; Hotez 2010; Hotez and Gurwith 2011; Cooper et al. 2012; Dowd et al. 2012; Hotez et al. 2012; Karan et al. 2012; Oxlade and Murray 2012; Bhutta et al. 2014; Hotez et al. 2014; Yang et al. 2015).

A third group of articles on poverty focused on the association of poverty with nutrition and physical health. Actually most of the points suggested by the Millennium Development Goals issued by the United Nations were directly or indirectly related to nutrition and, in fact, the first goal in the plan was to eradicate hunger (Tanumihardjo et al. 2007). Studies have shown that poverty or food insecurity is associated with lower quality diets which might affect the biological health of people and their life span (Champagne et al. 2007; Crimmins et al. 2009). Vulnerable groups of people like pregnant women are highly affected by poverty and food insecurity (Braveman et al. 2010). Poverty have been linked to increased prevalence of kidney diseases, diabetes, diabetic foot amputation, hypertension and cardiovascular diseases, and osteoporotic fractures (Wachtel 2005; Seedat 2007; Navarro et al. 2009; McClellan et al. 2010; Hsu et al. 2012; Booth et al. 2013; Gaskin et al. 2014). Obesity have also been associated with poverty and such association might be due to lack of physical activity or consumption of larger amounts of carbohydrates (Miech et al. 2006; Prentice and Webb 2006; Drewnowski et al. 2009; Ziol-Guest et al. 2009; Usfar et al. 2010).

A fourth dimension in retrieved articles was health policies to face poverty as global or national public health burden (McGarry and Schoeni 2005; Mahmud Khan et al. 2006; Meessen et al. 2006; Woolf et al. 2006; Ferguson et al. 2007; Limwattananon et al. 2007; Khun and Manderson 2008; Kruk et al. 2008; Zimmer 2008; Garg and Karan 2009; Schneider et al. 2009; Falkingham 
et al. 2010; Leatherman and Dunford 2010; Shahrawat and Rao 2012; Bhutta et al. 2014). Such articles focused on raising calls for implementation of economic plans for better distribution of national wealth to help poor people to get access to medicines and healthcare. The above mentioned main dimensions of retrieved articles were visualized in the density visualization map presented in Fig. 2.

Our study has few limitations related to nature of bibliometric studies (Sweileh et al. 2013, 2014; Zyoud et al. 2015a, b, c, d). False positive and false negative results are difficult to avoid regardless of how accurate the search stagey was. However, we believe that false positive or negative results were very marginal and could hardly affect the accuracy of the results of our study. Search strategy using title search increased the accuracy and minimized false positive results. One might argue against such strategy, but we thought it will be unfair to include all articles with the keyword "poverty" in title-abstractkeywords. Limiting search query to article title increased the accuracy of retrieved articles.

\section{Conclusions}

To the best of our knowledge, this is the first worldwide bibliometric study on poverty publications in relation to medicine. The results of our study showed that poverty research has been slowly progressing without any major or significant dominant leadership for any institution or author or journal. However, the leadership of the USA in the number of publications was evident. There is a prominent focus on poverty research in relation to infectious diseases and child development as demonstrated by the title of top cited articles. Given the global burden of poverty, inter-country collaboration among the top active found in this study is not up to the global challenge of poverty.

\section{Abbreviations}

h-index: the Hirsch index; IF: impact Factor; USA: Unite States of America; UK: United Kingdom; WHO: World Health Organization.

\section{Authors' contributions}

WS: concept and idea; and manuscript preparation and submission. SZ: data analysis and result section. AS and SA: literature review, critical thinking, data interpretation and manuscript preparation. All authors read and approved the final manuscript.

\section{Author details \\ ${ }^{1}$ Department of Physiology, Pharmacology, and Toxicology, College of Medi- cine and Health Sciences, An-Najah National University, Nablus, Palestine. ${ }^{2}$ Department of Clinical and Community Pharmacy, College of Medicine and Health Sciences, An-Najah National University, Nablus, Palestine.}

\section{Acknowledgements}

None.

\section{Competing interests}

The authors declare that they have no competing interests.

\section{Availability of data and materials}

All data present in this article can be retrieved from Scopus using keywords listed in the methodology.

Received: 25 May 2016 Accepted: 21 October 2016

Published online: 28 October 2016

\section{References}

Alvar J, Yactayo S, Bern C (2006) Leishmaniasis and poverty. Trends Parasitol 22(12):552-557

Alvarado-Esquivel C, Campillo-Ruiz F, Liesenfeld O (2013) Seroepidemiology of infection with Toxoplasma gondii in migrant agricultural workers living in poverty in Durango, Mexico. Parasit Vectors 6(1):113

Bhattacharya J, Currie J, Haider S (2004) Poverty, food insecurity, and nutritional outcomes in children and adults. J Health Econ 23(4):839-862

Bhutta ZA, Sommerfeld J, Lassi ZS, Salam RA, Das JK (2014) Global burden, distribution, and interventions for infectious diseases of poverty. Infect Dis Poverty 3(1):21

Blair C, Granger DA, Willoughby M, Mills-Koonce R, Cox M, Greenberg MT, Kivlighan KT, Fortunato CK (2011) Salivary cortisol mediates effects of poverty and parenting on executive functions in early childhood. Child Dev 82(6):1970-1984

Booth GL, Creatore MI, Moineddin R, Gozdyra P, Weyman JT, Matheson FI, Glazier RH (2013) Unwalkable neighborhoods, poverty, and the risk of diabetes among recent immigrants to Canada compared with longterm residents. Diabetes Care 36(2):302-308

Braveman P, Marchi K, Egerter S, Kim S, Metzler M, Stancil T, Libet M (2010) Poverty, near-poverty, and hardship around the time of pregnancy. Matern Child Health J 14(1):20-35

Breugelmans JG, Makanga MM, Cardoso AL, Mathewson SB, Sheridan-Jones BR, Gurney KA, Mgone CS (2015) Bibliometric assessment of European and sub-Saharan African research output on poverty-related and neglected infectious diseases from 2003 to 2011. PLoS Negl Trop Dis 9(8):e0003997

Buve A, Bishikwabo-Nsarhaza K, Mutangadura G (2002) The spread and effect of HIV-1 infection in sub-Saharan Africa. Lancet 359(9322):2011-2017

Calisher CH (2007) Poverty, human development, and infectious diseases. Croat Med J 48(5):755-758

Centers for Disease Prevention and Control (2016) Parasites—neglected parasitic infections (NPIs). Centers for Disease Prevention and Control. http://www.cdc.gov/parasites/npi/index.html. Accessed 10 Oct 2016

Champagne CM, Casey PH, Connell CL, Stuff JE, Gossett JM, Harsha DW, McCabe-Sellers B, Robbins JM, Simpson PM, Weber JL, Bogle ML (2007) Poverty and food intake in rural America: diet quality is lower in food insecure adults in the Mississippi Delta. J Am Diet Assoc 107(11):1886-1894

Choi SY, Holroyd E (2007) The influence of power, poverty and agency in the negotiation of condom use for female sex workers in mainland China. Cult Health Sex 9(5):489-503

Cooper PJ, Rodrigues LC, Barreto ML (2012) Influence of poverty and infection on asthma in Latin America. Curr Opin Allergy Clin Immunol 12(2):171-178

Crimmins EM, Kim JK, Seeman TE (2009) Poverty and biological risk: the earlier "aging" of the poor. J Gerontol A Biol Sci Med Sci 64(2):286-292

Das J, Do QT, Friedman J, McKenzie D, Scott K (2007) Mental health and poverty in developing countries: revisiting the relationship. Soc Sci Med 65(3):467-480

de la Barra X (1998) Poverty: the main cause of III health in urban children. Health Educ Behav 25(1):46-59

Dowd JB, Palermo TM, Aiello AE (2012) Family poverty is associated with cytomegalovirus antibody titers in U.S. children. Health Psychol 31(1):5-10

Drewnowski A, Rehm C, Kao C, Goldstein H (2009) Poverty and childhood overweight in California assembly districts. Health Place 15(2):631-635

Duncan GJ, Ziol-Guest KM, Kalil A (2010) Early-childhood poverty and adult attainment, behavior, and health. Child Dev 81(1):306-325

Emerson E (2007) Poverty and people with intellectual disabilities. Ment Retard Dev Disabil Res Rev 13(2):107-113 
Falagas ME, Pitsouni El, Malietzis GA, Pappas G (2008) Comparison of PubMed, Scopus, Web of Science, and Google Scholar: strengths and weaknesses. FASEB J 22(2):338-342

Falkingham J, Akkazieva B, Baschieri A (2010) Trends in out-of-pocket payments for health care in Kyrgyzstan, 2001-2007. Health Policy Plan 25(5):427-436

Fallah MP, Skrip LA, Gertler S, Yamin D, Galvani AP (2015) Quantifying poverty as a driver of Ebola transmission. PLoS Negl Trop Dis 9(12):e0004260

Farah MJ, Shera DM, Savage JH, Betancourt L, Giannetta JM, Brodsky NL, Malmud EK, Hurt H (2006) Childhood poverty: specific associations with neurocognitive development. Brain Res 1110(1):166-174

Feasey N, Wansbrough-Jones M, Mabey DC, Solomon AW (2010) Neglected tropical diseases. Br Med Bull 93(1):179-200

Ferguson H, Bovaird S, Mueller M (2007) The impact of poverty on educational outcomes for children. Paediatr Child Health 12(8):701-706

Ferreira FHG, Ravallion M (2008) Global poverty and inequality: a review of the evidence. World Bank Policy Research Working Paper Series, Vol

Fox AM (2010) The social determinants of HIV serostatus in sub-Saharan Africa: an inverse relationship between poverty and HIV? Public Health Rep 125(SUPPL. 4):16-24

Friis H, Michaelsen KF (1998) Micronutrients and HIV infection: a review. Eur J Clin Nutr 52(3):157-163

Galea S, Ahern J, Nandi A, Tracy M, Beard J, Vlahov D (2007) Urban neighborhood poverty and the incidence of depression in a population-based cohort study. Ann Epidemiol 17(3):171-179

Garg CC, Karan AK (2009) Reducing out-of-pocket expenditures to reduce poverty: a disaggregated analysis at rural-urban and state level in India. Health Policy Plan 24(2):116-128

Gaskin DJ, Thorpe RJ Jr, McGinty EE, Bower K, Rohde C, Young JH, LaVeist TA, Dubay L (2014) Disparities in diabetes: the nexus of race, poverty, and place. Am J Public Health 104(11):2147-2155

Gonzalez-Block MA, Vargas-Riano EM, Sonela N, Idrovo AJ, Ouwe-MissiOukem-Boyer O, Monot JJ (2011) Research capacity for institutional collaboration in implementation research on diseases of poverty. Trop Med Int Health 16(10):1285-1290

Grant KE, McCormick A, Poindexter L, Simpkins T, Janda CM, Thomas KJ, Campbell A, Carleton R, Taylor J (2005) Exposure to violence and parenting as mediators between poverty and psychological symptoms in urban African American adolescents. J Adolesc 28(4):507-521

Gryseels B, Zumla A, Troye-Blomberg M, Kieny MP, Quaglio G, Holtel A, Laang H, Romaris M, De Magistris MT, Nuez AN, Olesen OF, Ghalouci R, Lonnroth A (2009) European Union conference on poverty-related diseases research. Lancet Infect Dis 9(6):334-337

Hair NL, Hanson JL, Wolfe BL, Pollak SD (2015) Association of child poverty, brain development, and academic achievement. JAMA Pediatr 169(9):822-829

Haustein KO (2006) Smoking and poverty. Eur J Cardiovasc Prev Rehabil 13(3):312-318

Hilson G (2009) Small-scale mining, poverty and economic development in sub-Saharan Africa: an overview. Resour Policy 34(1-2):1-5

Hirsch JE (2005) An index to quantify an individual's scientific research output. Proc Natl Acad Sci USA 102(46):16569-16572

Hotez PJ (2008) Neglected infections of poverty in the United States of America. PLoS Negl Trop Dis 2(6):e256

Hotez PJ (2010) Neglected infections of poverty among the indigenous peoples of the arctic. PLoS Negl Trop Dis 4(1):e606

Hotez PJ, Gurwith M (2011) Europe's neglected infections of poverty. Int J Infect Dis 15(9):e611-e619

Hotez PJ, Wilkins PP (2009) Toxocariasis: America's most common neglected infection of poverty and a helminthiasis of global importance? PLoS Negl Trop Dis 3(3):e400

Hotez P, Ottesen E, Fenwick A, Molyneux D (2006) The neglected tropical diseases: the ancient afflictions of stigma and poverty and the prospects for their control and elimination. In: Pollard AJ, Finn A (eds) Hot topics in infection and immunity in children III. Springer, Berlin, pp 23-33

Hotez PJ, Brindley PJ, Bethony JM, King CH, Pearce EJ, Jacobson J (2008) Helminth infections: the great neglected tropical diseases. J Clin Invest 118(4):1311-1321

Hotez PJ, Bottazzi ME, Dumonteil E, Valenzuela JG, Kamhawi S, Ortega J, Rosales SP, Cravioto MB, Tapia-Conyer R (2012) Texas and Mexico: sharing a legacy of poverty and neglected tropical diseases. PLoS Negl Trop Dis 6(3):e1497

Hotez PJ, Murray KO, Buekens P (2014) The Gulf Coast: a new American underbelly of tropical diseases and poverty. PLoS Negl Trop Dis 8(5):e2760

Hsu CC, Lee CH, Wahlqvist ML, Huang HL, Chang HY, Chen L, Shih SF, Shin SJ, Tsai WC, Chen T, Huang CT, Cheng JS (2012) Poverty increases type 2 diabetes incidence and inequality of care despite universal health coverage. Diabetes Care 35(11):2286-2292

Huamani C, Rey de Castro J, Gonzalez-Alcaide G, Polesel DN, Tufik S, Andersen ML (2015) Scientific research in obstructive sleep apnea syndrome: biblometric analysis in SCOPUS, 1991-2012. Sleep Breath 19(1):109-114

Huntington D (2012) Health systems perspectives-infectious diseases of poverty. Infect Dis Poverty 1(1):12

Jackson S, Sleigh AC, Wang GJ, Liu XL (2006) Poverty and the economic effects of TB in rural China. Int J Tuberc Lung Dis 10(10):1104-1110

Kalichman SC, Simbayi LC, Jooste S, Cherry C, Cain D (2005) Poverty-related stressors and HIV/AIDS transmission risks in two South African communities. J Urban Health 82(2):237-249

Kalichman SC, Hernandez D, Cherry C, Kalichman MO, Washington C, Grebler T (2014) Food insecurity and other poverty indicators among people living with HIV/AIDS: effects on treatment and health outcomes. J Community Health 39(6):1133-1139

Karan A, Chapman GB, Galvani A (2012) The influence of poverty and culture on the transmission of parasitic infections in rural Nicaraguan villages. J Parasitol Res 2012:478292

Katabira ET, Oelrichs RB (2007) Scaling up antiretroviral treatment in resourcelimited settings: successes and challenges. AIDS 21 (Suppl 4):S5-S10

Khun S, Manderson L (2008) Poverty, user fees and ability to pay for health care for children with suspected dengue in rural Cambodia. Int J Equity Health 7:10

Kim JY, Chan M (2013) Poverty, health, and societies of the future. JAMA 310(9):901-902

King CH (2010) Parasites and poverty: the case of schistosomiasis. Acta Trop 113(2):95-104

Kinyanda E, Woodburn P, Tugumisirize J, Kagugube J, Ndyanabangi S, Patel V (2011) Poverty, life events and the risk for depression in Uganda. Soc Psychiatry Psychiatr Epidemiol 46(1):35-44

Kruk ME, Mbaruku G, Rockers PC, Galea S (2008) User fee exemptions are not enough: out-of-pocket payments for 'free' delivery services in rural Tanzania. Trop Med Int Health 13(12):1442-1451

Leatherman S, Dunford C (2010) Linking health to microfinance to reduce poverty. Bull World Health Organ 88(6):470-471

Limwattananon S, Tangcharoensathien V, Prakongsai P (2007) Catastrophic and poverty impacts of health payments: results from national household surveys in Thailand. Bull World Health Organ 85(8):600-606

Lovisi GM, Lopez JR, Coutinho ES, Patel V (2005) Poverty, violence and depression during pregnancy: a survey of mothers attending a public hospital in Brazil. Psychol Med 35(10):1485-1492

Lund C, De Silva M, Plagerson S, Cooper S, Chisholm D, Das J, Knapp M, Patel V (2011) Poverty and mental disorders: breaking the cycle in low-income and middle-income countries. Lancet 378(9801):1502-1514

MacDonald R (2005) Prioritising neglected diseases related to poverty. BMJ 331(7507):12

Mahmud Khan M, Hotchkiss DR, Berruti AA, Hutchinson PL (2006) Geographic aspects of poverty and health in Tanzania: does living in a poor area matter? Health Policy Plan 21(2):110-122

Marmot M (2016) The disease of poverty. Sci Am 314(3):23-24

Mbirimtengerenji ND (2007) Is HIV/AIDS epidemic outcome of poverty in subSaharan Africa? Croat Med J 48(5):605-617

McClellan WM, Newsome BB, McClure LA, Howard G, Volkova N, Audhya P, Warnock DG (2010) Poverty and racial disparities in kidney disease: the REGARDS study. Am J Nephrol 32(1):38-46

McGarry K, Schoeni RF (2005) Widow(er) poverty and out-of-pocket medical expenditures near the end of life. J Gerontol B Psychol Sci Soc Sci 60(3):S160-S168

Meessen B, Van Damme W, Tashobya CK, Tibouti A (2006) Poverty and user fees for public health care in low-income countries: lessons from Uganda and Cambodia. Lancet 368(9554):2253-2257

Miech RA, Kumanyika SK, Stettler N, Link BG, Phelan JC, Chang VW (2006) Trends in the association of poverty with overweight among US adolescents, 1971-2004. JAMA 295(20):2385-2393 
Mossakowski KN (2008) Is the duration of poverty and unemployment a risk factor for heavy drinking? Soc Sci Med 67(6):947-955

Mulia N, Schmidt L, Bond J, Jacobs L, Korcha R (2008) Stress, social support and problem drinking among women in poverty. Addiction 103(8):1283-1293

Nandy S, Irving M, Gordon D, Subramanian SV, Smith GD (2005) Poverty, child undernutrition and morbidity: new evidence from India. Bull World Health Organ 83(3):210-216

Nattrass N (2009) Poverty, sex and HIV. AIDS Behav 13(5):833-840

Navarro MC, Sosa M, Saavedra P, Lainez P, Marrero M, Torres M, Medina CD (2009) Poverty is a risk factor for osteoporotic fractures. Osteoporos Int 20(3):393-398

Nikulina V, Widom CS, Czaja S (2011) The role of childhood neglect and childhood poverty in predicting mental health, academic achievement and crime in adulthood. Am J Community Psychol 48(3-4):309-321

Oxlade O, Murray M (2012) Tuberculosis and poverty: why are the poor at greater risk in India? PLOS ONE 7(11):e47533

Perese EF (2007) Stigma, poverty, and victimization: roadblocks to recovery for individuals with severe mental illness. J Am Psychiatr Nurses Assoc 13(5):285-295

Piazza JA (2006) Rooted in poverty?: terrorism, poor economic development, and social cleavages 1. Terror Polit Violence 18(1):159-177

Piwoz EG, Preble EA (2000) HIV/AIDS and nutrition: a review of the literature and recommendations for nutritional care and support in sub-Saharan Africa. http://pdf.usaid.gov/pdf_docs/PNACK673.pdf. Accessed 12 Oct 2016

Prentice A, Webb F (2006) Obesity amidst poverty. Int J Epidemiol 35(1):24-30

Pritchett B (2014) Fighting poverty in the twenty-first century: conditions, contributors, problems, and solutions. http://bpritchett.pbworks.com/w/ file/fetch/81247934/FightingPoverty.pdf. Accessed 12 Oct 2016

Riley ED, Gandhi M, Bradley Hare C, Cohen J, Hwang SW (2007) Poverty, unstable housing, and HIV infection among women living in the United States. Curr HIV/AIDS Rep 4(4):181-186

Schneider M, Bradshaw D, Steyn K, Norman R, Laubscher R (2009) Poverty and non-communicable diseases in South Africa. Scand J Public Health 37(2):176-186

Seedat YK (2007) Impact of poverty on hypertension and cardiovascular disease in sub-Saharan Africa. Cardiovasc J Afr 18(5):316-320

Shahrawat R, Rao KD (2012) Insured yet vulnerable: out-of-pocket payments and India's poor. Health Policy Plan 27(3):213-221

Shisana O, Rice K, Zungu N, Zuma K (2010) Gender and poverty in South Africa in the era of HIV/AIDS: a quantitative study. JWomens Health (Larchmt) 19(1):39-46

Silveira MF, Santos IS, Victora CG (2008) Poverty, skin colour and HIV infection: a case-control study from southern Brazil. AIDS Care 20(3):267-272

Smith LM, LaGasse LL, Derauf C, Grant P, Shah R, Arria A, Huestis M, Haning W, Strauss A, Della Grotta S, Liu J, Lester BM (2006) The infant development, environment, and lifestyle study: effects of prenatal methamphetamine exposure, polydrug exposure, and poverty on intrauterine growth. Pediatrics 118(3):1149-1156

Subramanian SV, Chen JT, Rehkopf DH, Waterman PD, Krieger N (2005) Racial disparities in context: a multilevel analysis of neighborhood variations in poverty and excess mortality among black populations in Massachusetts. Am J Public Health 95(2):260-265

Sweileh WM, Zyoud SH, Sawalha AF, Abu-Taha A, Hussein A, Al-Jabi SW (2013) Medical and biomedical research productivity from Palestine, 2002-2011. BMC Res Notes 6:41

Sweileh WM, Al-Jabi SW, Zyoud SH, Sawalha AF (2014) Bronchial asthma and chronic obstructive pulmonary disease: research activity in Arab countries. Multidiscip Respir Med 9(1):38

Szwarcwald CL, Andrade CL, Bastos FI (2002) Income inequality, residential poverty clustering and infant mortality: a study in Rio de Janeiro, Brazil. Soc Sci Med 55(12):2083-2092

Tanumihardjo SA, Anderson C, Kaufer-Horwitz M, Bode L, Emenaker NJ, Haqq AM, Satia JA, Silver HJ, Stadler DD (2007) Poverty, obesity, and malnutrition: an international perspective recognizing the paradox. J Am Diet Assoc 107(11):1966-1972

Thompson DR, Clark AM (2015) Measuring research success via bibliometrics: where they fit and how they help and hinder. J Adv Nurs 71(12):2699-2701

Thompson DF, Walker CK (2015) A descriptive and historical review of bibliometrics with applications to medical sciences. Pharmacotherapy 35(6):551-559
Thurlow J, Gow J, George G (2009) HIV/AIDS, growth and poverty in KwaZuluNatal and South Africa: an integrated survey, demographic and economy-wide analysis. J Int AIDS Soc 12(1):18

Tladi LS (2006) Poverty and HIV/AIDS in South Africa: an empirical contribution. Sahara J 3(1):369-381

Tracy M, Zimmerman FJ, Galea S, McCauley E, Stoep AV (2008) What explains the relation between family poverty and childhood depressive symptoms? J Psychiatr Res 42(14):1163-1175

Tsai AC, Bangsberg DR, Weiser SD (2013) Harnessing poverty alleviation to reduce the stigma of HIV in sub-Saharan Africa. PLoS Med 10(11):e1001557

Usfar AA, Lebenthal E, Atmarita Achadi E, Soekirman Hadi H (2010) Obesity as a poverty-related emerging nutrition problems: the case of Indonesia. Obes Rev 11(12):924-928

van Doorslaer E, O'Donnell O, Rannan-Eliya RP, Somanathan A, Adhikari SR, Garg CC, Harbianto D, Herrin AN, Huq MN, Ibragimova S, Karan A, $\mathrm{Ng}$ CW, Pande BR, Racelis R, Tao S, Tin K, Tisayaticom K, Trisnantoro L, Vasavid C, Zhao Y (2006) Effect of payments for health care on poverty estimates in 11 countries in Asia: an analysis of household survey data. Lancet 368(9544):1357-1364

van Eck NJ, Waltman L (2010) Software survey: VOSviewer, a computer program for bibliometric mapping. Scientometrics 84(2):523-538

von Philipsborn P, Steinbeis F, Bender ME, Regmi S, Tinnemann P (2015) Poverty-related and neglected diseases — an economic and epidemiological analysis of poverty relatedness and neglect in research and development. Glob Health Action 8:25818

Wachtel MS (2005) Family poverty accounts for differences in lower-extremity amputation rates of minorities 50 years old or more with diabetes. J Natl Med Assoc 97(3):334-338

Wheeler BW, Rigby JE, Huriwai T (2006) Pokies and poverty: problem gambling risk factor geography in New Zealand. Health Place 12(1):86-96

Whiteside A (2010) Poverty and HIV/AIDS in Africa. Third world quarterly 23(2):313-332

Wight V, Kaushal N, Waldfogel J, Garfinkel I (2014) Understanding the link between poverty and food insecurity among children: does the definition of poverty matter? J Child Poverty 20(1):1-20

Woolf SH, Johnson RE, Geiger HJ (2006) The rising prevalence of severe poverty in America: a growing threat to public health. Am J Prev Med 31(4):332-341

World Health Organization (2016) Poverty and health. WHO. http://www.who. int/hdp/poverty/en/. Accessed 12 Oct 2016

Yang GJ, Utzinger J, Zhou XN (2015) Interplay between environment, agriculture and infectious diseases of poverty: case studies in China. Acta Trop 141 (Pt B):399-406

Yoshikawa H, Aber JL, Beardslee WR (2012) The effects of poverty on the mental, emotional, and behavioral health of children and youth: implications for prevention. Am Psychol 67(4):272-284

Zenk SN, Schulz AJ, Israel BA, James SA, Bao S, Wilson ML (2005) Neighborhood racial composition, neighborhood poverty, and the spatial accessibility of supermarkets in metropolitan Detroit. Am J Public Health 95(4):660-667

Zimmer Z (2008) Poverty, wealth inequality and health among older adults in rural Cambodia. Soc Sci Med 66(1):57-71

Ziol-Guest KM, Duncan GJ, Kalil A (2009) Early childhood poverty and adult body mass index. Am J Public Health 99(3):527-532

Zyoud SH, Al-Jabi SW, Sweileh WM, Al-Khalil S, Alqub M, Awang R (2015a) Global methaemoglobinaemia research output (1940-2013): a bibliometric analysis. Springerplus 4:626

Zyoud SH, Al-Jabi SW, Sweileh WM, Awang R, Waring WS (2015b) Bibliometric profile of the global scientific research on methanol poisoning (1902-2012). J Occup Med Toxicol 10:17

Zyoud SH, Al-Jabi SW, Sweileh WM, Awang R, Waring WS (2015c) Global research productivity of $\mathrm{N}$-acetylcysteine use in paracetamol overdose: a bibliometric analysis (1976-2012). Hum Exp Toxicol 34(10):1006-1016

Zyoud SH, Al-Jabi SW, Sweileh WM, Waring WS (2015d) Scientific research related to calcium channel blockers poisoning: bibliometric analysis in Scopus, 1968-2012. Hum Exp Toxicol 34(11):1162-1170 